\title{
Life Space Assessment in Older Women Undergoing Non-Surgical Treatment for Urinary Incontinence
}

\author{
Thomas L. Wheeler II ${ }^{*}$, Jana D. Illston'1, Alayne D. Markland ${ }^{2}$, Patricia S. Goode ${ }^{2}$, \\ Holly E. Richter ${ }^{3}$ \\ ${ }^{1}$ Department of Obstetrics and Gynecology, University of South Carolina School of Medicine-Greenville, \\ Greenville, USA \\ ${ }^{2}$ Division of Gerontology, Geriatrics and Palliative Care, University of Alabama at Birmingham, Birmingham, USA \\ ${ }^{3}$ Department of Obstetrics and Gynecology, University of Alabama at Birmingham, Birmingham, USA \\ Email: ${ }^{*}$ TWheelerlIMD@ghs.org
}

Received 4 July 2014; revised 3 August 2014; accepted 1 September 2014

Copyright @ 2014 by authors and Scientific Research Publishing Inc.

This work is licensed under the Creative Commons Attribution International License (CC BY).

http://creativecommons.org/licenses/by/4.0/

c) (i) Open Access

\section{Abstract}

Objective: Urinary incontinence (UI) impacts all aspects of life activities. This study aims to characterize change in mobility within the community utilizing the Life Space Assessment (LSA) questionnaire in women undergoing non-surgical UI treatment. Methods: This prospective cohort study, performed from July 2007 to March 2009, followed women seeking non-surgical UI treatment from an outpatient tertiary-care clinic and assessed their mobility and symptoms using LSA, Urogenital Distress Inventory (UDI-6), and Incontinence Impact Questionnaire (IIQ-7) at baseline and 2, 6, and 12 months post-treatment. Estimated Percent Improvement (EPI) and Patient Satisfaction Question (PSQ) were obtained post-treatment. The women were treated with multi-component behavioral and/or pharmacologic therapies, and we hypothesized that LSA would improve with treatment. Repeated measures analysis with Tukey's HSD and backwards selection linear regression model were performed. Results: 70 ambulatory, community-dwelling women, aged 65 years or older, seeking non-surgical care for UI were recruited. LSA score decreased from baseline to 2 months (mean \pm SD; $63 \pm 29$ to $56 \pm 28$, p < 0.001) and was sustained at 6 and 12 months (54 \pm $28,54 \pm 28$ ). UDI scores improved from $36 \pm 23$ to $25 \pm 24$, p $<0.001$, at 2 months, and improvement persisted at 6 and 12 months $(22 \pm 22,21 \pm 24)$. Improvements in UDI and patient perceived improvement in UI were not associated with LSA change. Age, race, and depression impacted LSA, which decreased 1-point for each additional year of age $(p=0.004), 6$-points for each point higher on the Geriatric Depression Scale (GDS) $(p=0.002)$, and 6-point for African American race ( $p=$ 0.048). Conclusion: Decreased mobility represented by LSA was related to age, depression, and race, but not UI symptom improvement.

\footnotetext{
"Corresponding author.
}

How to cite this paper: Wheeler II, T.L., Illston, J.D., Markland, A.D., Goode, P.S. and Richter, H.E. (2014) Life Space Assessment in Older Women Undergoing Non-Surgical Treatment for Urinary Incontinence. Open Journal of Obstetrics and Gynecology, 4, 809-816. http://dx.doi.org/10.4236/ojog.2014.414112 


\section{Keywords}

\section{Urinary Incontinence, Life-Space, Depression, Mobility, Community-Dwelling Women}

\section{Introduction}

Urinary incontinence (UI) prevalence ranges from 30\% - 50\% and is associated with significant morbidity and impact on quality of life in older women [1] [2]. Non-surgical therapies provide successful short-term improvements and even cure in some women with UI [3]-[6]. These treatment regimens include medications and behavioral therapy, which is comprised of pelvic floor muscle exercises, fluid management, and bladder control strategies. In older women, UI has been shown to be associated with impaired mobility, functional limitations, and falls [7]-[12]. Conversely, the effect of treating incontinence on mobility is unknown.

Typically, mobility and functional status have been measured indirectly using surrogates, such as the 6Minute Walk Test, Activities of Daily Living (ADLs), and Instrumental ADLs (IADLS), rather than directly measuring the patient's "real life" global mobility. The actual impact of conditions such as UI on global mobility may be underestimated using these surrogate measures [10] [13] [14]. The validated Life Space Assessment (LSA) for older adults was designed to fill this void by assessing global mobility from the patient perspective, with respect to activity in the home environment and community, over the previous 4 weeks [15] [16]. The LSA is based on a conceptual model of actual mobility as a series of concentric rings radiating from the room where a person sleeps, out through their home and town, to an unlimited space away. In fact, when studied in Alabama Medicare beneficiaries, IADLs and ADLs only accounted for 33\% of the variance in LSA, highlighting the need to look at other factors impacting mobility [16]. The concept of Life-Space may be particularly important for women with incontinence due to fear of visible leakage or odor, and its potential impact on travel outside the home and within the community. Thus, we hypothesized that mobility may improve with successful treatment of incontinence.

The primary objective of this study was to assess changes in mobility, as measured by the LSA, prospectively over a 1-year period in community dwelling women 65 years of age and older who received individualized non-surgical treatment for UI.

\section{Methods}

After IRB approval, ambulatory women, aged 65 years or older, who were seeking non-surgical treatment for UI were recruited for participation in this study from July 2007 to March 2009. Women with dementia, current use of anti-muscarinic medication, neurological disease, poorly controlled medical disease (i.e. Hgb A1C > 9, decompensated congestive heart failure), elevated PVR (>150 cc), use of catheterization, unevaluated hematuria, current UTI, fecal impaction, recent bladder surgery, vaginal prolapse beyond the hymen, neuromodulation, bladder augmentation, and ongoing treatment for incontinence at other facilities were excluded.

Qualified participants provided written, informed consent and underwent a clinical evaluation including interview, physical examination, and validated questionnaires (Incontinence Impact Questionnaire (IIQ-7), Urinary Distress Inventory (UDI-6), Patient Satisfaction Question (PSQ), 5-item Geriatric Depression Scale (GDS)) [17] [18]. 6-minute walk and Charlson Co-morbidity Index, which is a weighted score based on comorbid disease, were also completed for each patient [19] [20]. Individualized non-surgical treatment was performed and included behavioral treatments with pelvic floor muscle exercises for improved strength and control, adaptive responses to sensation of urgency, bladder training to increase voiding intervals, stress strategies to avoid incontinence with activity, fluid management, and caffeine avoidance. Anti-muscarinic bladder medications were added as clinically indicated.

Patients were initially seen every 2 - 3 weeks and then visits were spaced out to every 2 - 3 months, after adequate symptom control had been achieved, and at one year. At 2, 6, and 12 months post initiation of therapy, patients were contacted by telephone for measurement of LSA. They also received the same questionnaires as at baseline, as well as the Estimated Percent Improvement measure, which they completed and returned by mail at those times. Two months (8 weeks) was chosen as the primary outcome time point as it is an assessment time point typically seen in conservative therapy (non-surgical) trials in incontinence [4] [5] [15] [16]. The 6 and 
12-month outcomes were included to show the trajectory of LSA and the relationship between LSA and improvements or regression in symptoms.

A ten-point decline in LSA has been associated with stopping travel outside of one's town, so this decrease was selected as the clinically relevant cutoff for significant change in LSA [21]. Preliminary data for baseline LSA scores from 33 patients undergoing gynecologic surgery had a standard deviation (SD) of 27, which is a conservative overestimate of the SD on the change in LSA. Therefore, with alpha $=0.05$, power $=0.80, S D=27$, and desired detectable difference of 10, the sample size needed was 59. Study enrollment was increased to 70 to allow for approximately $20 \%$ attrition.

Multivariable linear regression with backwards selection, including repeated measures analysis, was performed with known covariates in the model to explore for potential predictors of LSA. The backwards selection process starts with all baseline parameters and removes parameters until all are statistically significant while keeping the known covariates of LSA were age, income, transportation difficulty and race given by the participant. Repeated measures with Tukey's HSD assessed for improvements in UDI-6, IIQ-7, and EPI. Logistic regression was used to assess PSQ. Analysis was performed with JMP 8 (Cary, NC).

\section{Results}

At baseline, 70 patients were enrolled and participated in the study. At 2, 6, and 12 months 66, 67, and 64 patients, respectively, followed up which resulted in an $8.6 \%$ attrition rate by 12 months. Patient characteristics are shown in Table 1. Mean age \pm SD was $74.9 \pm 6.8$ years.

LSA score significantly decreased, reflecting lack of improvement, from baseline to 2 months $(\mathrm{p} \leq 0.001)$ and was maintained at 6 months and 12 months (mean \pm SD; baseline $63 \pm 29$, 2 months $56 \pm 28,6$ months $54 \pm 28$, 12 months $54 \pm 28$ ) (Figure 1). UDI scores improved from $36 \pm 23$ to $25 \pm 24$ at 2 months ( $<0.001$ ), and improvement persisted at 12 months (Table 2). IIQ-7 scores did not significantly change at 2, 6, or 12 months ( $\mathrm{p}=$ 0.345). Patient-reported Estimated Percent Improvement at 2 months was $45 \%$ and was maintained to 12 months ( $p=0.509$ ). Patient satisfaction reflected $23 \%$ of women completely satisfied, $58 \%$ somewhat satisfied and $19 \%$ not at all satisfied at 2 months, which did not change significantly up to 12 months ( $\mathrm{p}=0.554)$.

Multivariable backwards modeling, controlling for known covariates of LSA, did not find improvements in UDI score or patient perceived improvement in UI to be associated with LSA assessment ( $>0.05)$. However, each additional year of age was associated with a 1-point LSA decrease $(\mathrm{p}=0.004)$, and each additional point on GDS was associated with a 6-point LSA decrease $(p=0.002)$. African America race was associated with a 6-point lower LSA $(p=0.048)$. Of note, BMI was eliminated as a potentially associated variable during the modeling.

\section{Discussion}

Non-surgical therapy for the treatment of symptomatic UI did not result in improvement in mobility, as measured by LSA scores over a 1-year period. Despite significant improvements in urinary symptoms after non-surgical treatment, there was no improvement in mobility. Community mobility actually declined overall for the

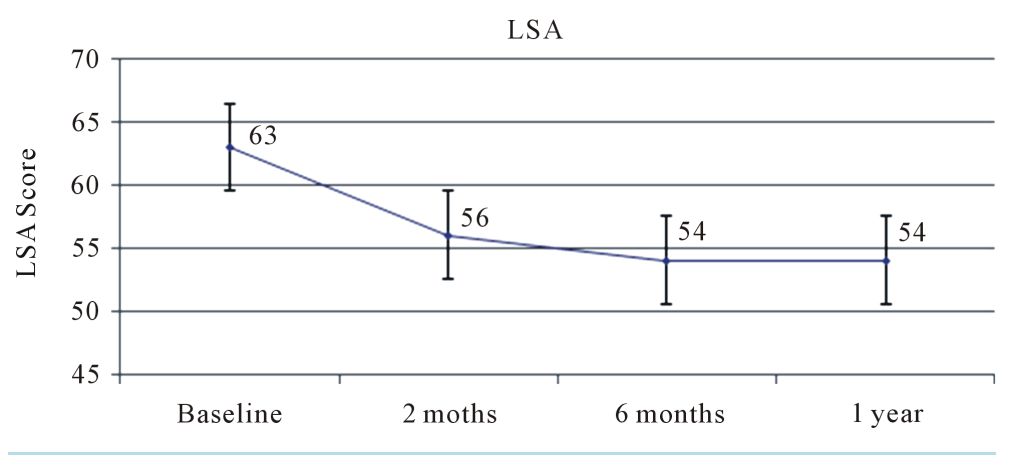

Figure 1. Changes in life space assessment $(0$ - 120) over 1 year in older women undergoing non-surgical treatment for urinary incontinence. $p<0.001$ between baseline and 2 months, sustained to 1 year; Life space assessment range $0-120$. 
Table 1. Patient clinical and demographic characteristics.

\begin{tabular}{lr}
\hline \multicolumn{1}{c}{ Demographics } & Mean $\pm \mathrm{SD}^{\mathrm{a}}$, Ran \\
\hline Age, Years & $75 \pm 7,65-90$ \\
$\mathrm{BMI}^{\mathrm{c}}, \mathrm{kg} / \mathrm{m}^{2}$ & $30 \pm 7,20-49$ \\
Race &
\end{tabular}

$\mathrm{N}^{\mathrm{b}}(\%)$

African American

$14(20)$

Caucasian

$56(80)$

Marital Status

Married

34 (49)

Divorced

10 (14)

Widowed

25 (36)

Single

$1(1)$

Living Arrangements

Lives with Spouse

Lives with Other Family

Lives in Nursing Home

Lives in Congregate Housing

Lives Alone

30 (43)

Transportation Difficulty

Limited Activity Due to Lack of Transportation

Yes

No

$61(87)$

Miles Traveled to Urogyn Office

$28 \pm 32,<1-168$

Previous Surgery for $\mathrm{UI}^{\mathrm{d}}$ or POP

Yes

$11(16)$

No

Smoker

Yes

No

Income

$<\$ 7999$

$\$ 8000$ - 15,999

$\$ 16,000$ - 29,999

$\$ 30,000$ - 49,999

17 (25)

$>50,000$

6 Minute Walk Distance, ft

$734 \pm 373,0-1490$

Assist Device Used

$\begin{array}{lc}\text { None } & 54(79) \\ \text { Walker } & 6(9) \\ \text { Cane } & 8(12)\end{array}$

5 Item Geriatric Depression Scale

$1 \pm 1,0-5$

Charlson Comorbidity Index Total Score

$3 \pm 2,0-9$

${ }^{\mathrm{a}} \mathrm{SD}$ (Standard Deviation); ${ }^{\mathrm{b}} \mathrm{N}$ (Number); ${ }^{\mathrm{B}} \mathrm{BMI}$ (Body Mass Index); ${ }^{\mathrm{d} U I}$ (Urinary Incontinence); ${ }^{\mathrm{e}} \mathrm{POP}$ (Pelvic Organ Prolapse). 
Table 2. Outcome measures.

\begin{tabular}{|c|c|c|c|}
\hline $\begin{array}{l}\text { Instrument } \\
\text { Time Point }\end{array}$ & Score (Mean $\pm \mathrm{SD}^{\mathrm{f}}$, Range) & $\mathrm{N}^{\mathrm{g}}(\%)$ & $\mathrm{p}-\mathrm{Val}^{\mathrm{h}}$ \\
\hline Incontinence Impact Questionnaire & (Range 0 - 100) & & 0.345 \\
\hline Baseline & $22 \pm 24,0-95$ & & \\
\hline 2 Months & $17 \pm 23,0-76$ & & \\
\hline 6 Months & $18 \pm 25,0-100$ & & \\
\hline 12 Months & $17 \pm 26,0-100$ & & \\
\hline Urogenital Distress Inventory & (Range 0 - 100) & & $<0.001$ \\
\hline Baseline & $36 \pm 23,0-83$ & & \\
\hline 2 Months & $25 \pm 24,0-89$ & & \\
\hline 6 Months & $22 \pm 22,0-89$ & & \\
\hline 12 Months & $21 \pm 24,0-89$ & & \\
\hline Satisfaction & & & 0.554 \\
\hline \multicolumn{4}{|l|}{2 Months } \\
\hline Completely & & $15(23)$ & \\
\hline Somewhat & & $38(58)$ & \\
\hline Not At All & & $12(18)$ & \\
\hline \multicolumn{4}{|l|}{6 Months } \\
\hline Completely & & $17(25)$ & \\
\hline Somewhat & & $34(51)$ & \\
\hline Not At All & & $16(24)$ & \\
\hline \multicolumn{4}{|l|}{12 Months } \\
\hline Completely & & $21(34)$ & \\
\hline Somewhat & & $27(44)$ & \\
\hline Not At All & & $14(23)$ & \\
\hline Estimated Percent Improvement & (Range 0 - 100) & & 0.509 \\
\hline 2 Months & $45 \pm 35,0-100$ & & \\
\hline 6 Months & $48 \pm 33,0-100$ & & \\
\hline 12 Months & $49 \pm 37,0-100$ & & \\
\hline
\end{tabular}

${ }_{\mathrm{f}}^{\mathrm{f}} \mathrm{SD}$ (Standard Deviation); ${ }^{\mathrm{g}} \mathrm{N}$ (Number); ${ }^{\mathrm{h}} \mathrm{p}$-value across all time points.

participants in this study. Age, race, and depression were factors significantly associated with the decline in mobility. Among older women with UI undergoing non-surgical treatment, our findings can be used to counsel patients that treatment of UI alone may not result in improved community mobility.

Perhaps the degree of improvement in urinary symptoms with this non-surgical treatment approach was not large enough to have an effect on improving community mobility in this cohort. A previous report noted the minimum clinically important difference for the long form UDI, which is scored 0 - 300, to be an improvement of 35 points [22]. The short form UDI, which was utilized in this study is scored $0-100$. We found an improvement in UDI scores of 11 points at 2 months and 15 points at 12 months. If we conservatively assume that a one-half standard deviation change reflects a clinically important difference, that would be a 12 point reduction at both the 2 and 12 month time-points [23]. We nearly did have this degree of change in UDI-7 score at 2 months and did meet this threshold at 12 months. Regardless, we did not find a positive change in LSA scores paralleling improvement in UI symptoms. If improved urinary symptoms affect community mobility, it is possi- 
ble that either we did not impact incontinence sufficiently for a mobility improvement, to create a difference in mobility scores as measured by the LSA, or that the measurement of urinary symptoms with the UDI-7 was not a sensitive enough measure of improvement. We chose not to subdivide the LSA analysis into groups with large changes in UDI-7 versus groups with no change or worsening in UDI-7 as these divisions would decrease the population sizes and could potentially bias our findings. Additionally, we elected to report the $a$ priori selected statistical analysis for this prospective study rather than changing to a retrospective analysis.

The actual decline in LSA scores that we noted among women with UI who sought conservative treatment were most likely influenced by other factors that also are associated with UI. Multiple studies have shown associations between depression or depressive symptoms and UI [8] [9] [11] [24] [25]. Quality of life and perception of one's health status also are correlated with depression and UI, and treating urgency UI has been shown to improve depressive symptoms [14] [26]-[31]. It is suggested from our results that the existence of depression over-rides improvement in UI symptoms. Depression is a modifiable condition, which when treated effectively could improve LSA. Interventions targeting depressive symptoms may augment the impact that treating UI has on an older patient's LSA. Older women may not be the only population where treating depression may have effects on UI as overweight women with depressive symptoms also report more UI and worse UDI scores [32]. Studies in Canadian and Australian women have also shown synergistic negative impact on QOL fordepression and incontinence [27] [28]. Future research with LSA in this population should also include a depression scale to account for confounding.

Strengths of this study include assessments with validated measures at 4 time points over a year while statistically adjusting for known covariates of LSA and multiple testing, and low attrition rate. Weaknesses include not having a control group, but we preferred to offer treatment per individualized usual care to all participants as they were recruited from a cohort of women seeking care. It is a disadvantage that the other, non-LSA mobility tests were only performed at baseline and not at post-treatment intervals as this may have given us complementary information regarding impact on mobility in a smaller life-space such as in the household. The tertiary care specialty clinic population may also limit generalizability to the primary care setting, and likewise, limiting the study to community-dwelling women may limit its application to women requiring residential care.

\section{Conclusion}

In conclusion, we did not find improvement in mobility within the community utilizing the validated LSA tool, with improvements in UI symptoms among women receiving non-surgical treatments per individualized usual care. However, larger cohort studies or clinical trials using the LSA when potentially greater improvements in UI are expected, such as surgical intervention, should be performed to better assess the relationship with UI and improvements in mobility related to urinary incontinence among older women.

\section{Disclosures}

Patricia S. Goode, MSN, MD was a recipient of a Pfizer research grant and was a consultant for Astellas. Holly E. Richter, PhD, MD receives NIH funding from NIDDK and NICHD, receives grant from and serves as a consultant for Pelvalon, receives royalties from Up To Date, and serves as an SGS board member.

\section{Author Contributions}

Study concept and design (TLW, ADM, PSG, HER), acquisition of subjects/data (TLW), analysis and interpretation of data (TLW, JDI), preparation of manuscript (TLW, JDI, ADM, PSG, HER).

\section{Funding}

Thomas L. Wheeler, II, MD, MSPH received funding for this study through the American Geriatric Society as a recipient of a Dennis W. Jahnigen Career Development Award. Further support at the time of the study was provided through Holly E. Richter, PhD, MD K24 NIH funding.

\section{References}

[1] Hunskaar, S., Arnold, E.P., Burgio, K.L., Diokno, A.C., Herzog, A.R. and Mallett, V.T. (2000) Epidemiology and Natural History of Urinary Incontinence. International Urogynecology Journal and Pelvic Floor Dysfunction, 11, 301- 


\section{9. http://dx.doi.org/10.1007/s001920070021}

[2] Diokno, A.C., Brock, B.M., Brown, D. and Herzog, A.R. (1986) Prevalence of Urinary Incontinence and Other Urologic Symptoms in the Noninstitutionalized Patient. Journal of Urology, 136, 1022-1025.

[3] Fantl, J.A., Wyman, J.F., McClish, D.K., Harkins, S.W., Elswick, R.K., Taylor, J.R., et al. (1991) Efficacy of Bladder Training in Older Women with Urinary Incontinence. JAMA, 265, 609-613. http://dx.doi.org/10.1001/jama.1991.03460050063021

[4] Burgio, K.L., Locher, J.L., Goode, P.S., Hardin, J.M., McDowell, B.J., Dombrowski, M., et al. (1998) Behavior vs Drug Treatment for Urge Urinary Incontinence in Older Women. JAMA, 280, 1995-2000. http://dx.doi.org/10.1001/jama.280.23.1995

[5] Goode, P.S., Burgio, K.L., Locher, J.L., Roth, D.L., Umlauf, M.G., Richter, H.E., et al. (2003) Effect of Behavioral Training with or without Pelvic Floor Electrical Stimulation on Stress Incontinence in Women: A Randomized Controlled Trial. JAMA, 290, 345-352. http://dx.doi.org/10.1001/jama.290.3.345

[6] Dumoulin, C. and Hay-Smith, J. (2010) Pelvic Floor Muscle Training versus No Treatment, or Inactive Control Treatments, for Urinary Incontinence in Women. Cochrane Database of Systematic Reviews, 1, Article ID: CD005654. http://dx.doi.org/10.1002/14651858.CD005654.pub2

[7] Jenkins, K.R. and Fultz, N.H. (2005) Functional Impairment as a Risk Factor for Urinary Incontinence among Older Americans. Neurology and Urodynamics, 24, 51-55.

[8] Matthews, C.A., Whitehead, W.E., Townsend, M.K. and Grodstein, F. (2013) Risk Factors for Urinary, Fecal, or Dual Incontinence in the Nurses’ Health Study. Obstetrics Gynecology, 122, 539-545. http://dx.doi.org/10.1097/AOG.0b013e31829efbff

[9] Melville, J.L., Fan, M.Y., Rau, H., Nygaard, I.E. and Katon, W.J. (2009) Major Depression and Urinary Incontinence in Women: Temporal Associations in an Epidemiologic Sample. American Journal of Obstetrics Gynecology, 201, 490.e1-e7.

[10] Bürge, E., Von Guten, A. and Berchtold, A. (2013) Factors Favoring a Degradation or an Improvement in Activities of Daily Living (ADL) Performance among Nursing Home (NH) Residents: A Survival Analysis. Archives of Gerontology and Geriatrics, 56, 250-257. http://dx.doi.org/10.1016/j.archger.2012.09.001

[11] Nuotio, M., Luukkaala, T., Tammela, T.L.J. and Jylhä, M. (2009) Six-Year Follow-Up and Predictors of UrgencyAssociated Urinary Incontinence and Bowel Symptoms among the Oldest Old: A Population-Based Study. Archives of Gerontology and Geriatrics, 49, e85-e90. http://dx.doi.org/10.1016/j.archger.2008.08.009

[12] Smith, A.L., Wang, P.C., Anger, J.T., Mangione, C.M., Trejo, L., Rodríguez, L.V. and Sarkisian, C.A. (2010) Correlates of Urinary Incontinence in Community Dwelling Older Latinos. Journal of the American Geriatrics Society, 58, 1170-1176. http://dx.doi.org/10.1111/j.1532-5415.2010.02814.x

[13] Verbrugge, L.M., Gruber, A.L. and Fozard, J.L. (1996) Age Differences and Age Changes in Activities: Baltimore Longitudinal Study of Aging. Journal of Gerontology Series B: Psychological Sciences and Social Sciences, 51B, S30S41. http://dx.doi.org/10.1093/geronb/51B.1.S30

[14] Bluestein, D. and Rutledge, C.M. (2006) Perceived Health and Geriatric Risk Stratification. Canadian Family Physician, 52, 626-627.

[15] Baker, P.S., Bodner, E.V. and Allman, R.M. (2003) Measuring Life-Space Mobility in Community-Dwelling Older Adults. Journal of the American Geriatrics Society, 51, 1610-1614. http://dx.doi.org/10.1046/j.1532-5415.2003.51512.x

[16] Peel, C., Baker, P.S., Roth, D.L., Brown, C.J., Bodner, E.V. and Allman, R.M. (2005) Assessing Mobility in Older Adults: The UAB Study of Aging Life-Space Assessment (University of Alabama at Birmingham). Physical Therapy, 12, 1008-1019.

[17] Burgio, K.L., Goode, P.S., Richter, H.E., Locher, J.L. and Roth, D.L. (2006) Global Ratings of Patient Satisfaction and Perceptions of Improvement with Treatment for Urinary Incontinence: Validation of Three Global Patient Ratings. Neurourology and Urodynamics, 25, 411-417. http://dx.doi.org/10.1002/nau.20243

[18] Uebersax, J.E., Wyman, J.F., Shumaker, S.A. and McClish, D.K. (1995) Short Forms to Assess Life Quality and Symptom Distress for Urinary Incontinence in Women: The Incontinence Impact Questionnaire and the Urogenital Distress Inventory. Neurourology and Urodynamics, 14, 131-139. http://dx.doi.org/10.1002/nau.1930140206

[19] Harada, N.D., Chiu, V. and Stewart, A.L. (1999) Mobility-Related Function in Older Adults: Assessment with a 6Minute Walk Test. Archives of Physical Medicine and Rehabilitation, 80, 837-841. http://dx.doi.org/10.1016/S0003-9993(99)90236-8

[20] Charlson, M.E., Pompei, P., Ales, K.L. and MacKenzie, C.R. (1987) A New Method of Classifying Prognostic Comorbidity in Longitudinal Studies: Development and Validation. Journal of Chronic Diseases, 40, 373-383. http://dx.doi.org/10.1016/0021-9681(87)90171-8 
[21] Allman, R.M., Baker, P.S., Maisak, R.M., Sims, R.V. and Roseman, J.M. (2004) Racial Similarities and Differences of Mobility Change over Eighteen Months. Journal of General Internal Medicine, 19, 1118-1126. http://dx.doi.org/10.1111/j.1525-1497.2004.30239.x

[22] Dyer, K.Y., Xu, Y., Brubaker, L., Nygaard, I., Markland, A., Rahn, D., et al. (2011) Minimum Important Difference for Validated Instruments in Women with Urge Incontinence. Neurourology and Urodynamics, 30, 1319-1324.

[23] Sloan, J.A., Cella, D. and Hays, R.D. (2005) Clinical Significance of Patient-Reported Questionnaire Data: Another Step toward Consensus. Journal of Clinical Epidemiology, 58, 1217-1219. http://dx.doi.org/10.1016/j.jclinepi.2005.07.009

[24] Nygaard, I., Turvey, C., Burns, T.L., Crischilles, E. and Wallace, R. (2003) Urinary Incontinence and Depression in Middle-Aged United States Women. Obstetrics \& Gynecology, 101, 149-156. http://dx.doi.org/10.1016/S0029-7844(02)02519-X

[25] Engberg, S., Sereika, S., Weber, E., Engberg, R., McDowell, B.J. and Reynolds, C.F. (2001) Prevalence and Recognition of Depressive Symptoms among Homebound Older Adults with Urinary Incontinence. Journal of Geriatric Psychiatry and Neurology, 14, 130-139. http://dx.doi.org/10.1177/089198870101400306

[26] Stach-Lempinen, B., Hakala, A.L., Laippala, P., Lehtinen, K., Metsänoja, R. and Kujansuu, E. (2003) Severe Depression Determines Quality of Life in Urinary Incontinent Women. Neurourology and Urodynamics, 22, 563-568. http://dx.doi.org/10.1002/nau.10137

[27] Avery, J.C., Stocks, N.P., Duggan, P., Braunack-Mayer, A.J., Taylor, A.W., Goldney, R.D. and MacLennan, A.H. (2013) Identifying the Quality of Life Effects of Urinary Incontinence with Depression in an Australian Population. BMC Urology, 13, 11. http://dx.doi.org/10.1186/1471-2490-13-11

[28] Vigod, S.N. and Stewart, D.E. (2006) Major Depression in Female Urinary Incontinence. Psychosomatics, 47, 147-151. http://dx.doi.org/10.1176/appi.psy.47.2.147

[29] Kafri, R., Kodesh, A., Shames, J., Golomb, J. and Melzer, I. (2013) Depressive Symptoms and Treatment of Women with Urgency Urinary Incontinence. International Urogynecology Journal, 24, 1953-1959.

[30] Knorst, M.R., Resende, T.L. and Goldim, J.R. (2011) Clinical Profile, Quality of Life and Depressive Symptoms of Women with Urinary Incontince Attending a University Hospital. Brazilian Journal of Physical Therapy, 15, 109-116. http://dx.doi.org/10.1590/S1413-35552011000200005

[31] Dugan, E., Cohen, S.J., Bland, D.R., Preisser, J.S., Davis, C.C., Suggs, P.K. and McGann, P. (2000) The Association of Depressive Symptoms and Urinary Incontinence among Older Adults. Journal of the American Geriatrics Society, 48, 413-416.

[32] Sung, V.W., West, D.S., Hernandez, A.L., Wheeler, T.L., Myers, D.L., Subak, L.L., Program to Reduce Incontinence by Diet and Exercise (PRIDE) (2009) Association between Urinary Incontinence and Depressive Symptoms in Overweight and Obese Women. American Journal of Obstetrics and Gynecology, 200, 557.e1-e5. 
Scientific Research Publishing (SCIRP) is one of the largest Open Access journal publishers. It is currently publishing more than 200 open access, online, peer-reviewed journals covering a wide range of academic disciplines. SCIRP serves the worldwide academic communities and contributes to the progress and application of science with its publication.

Other selected journals from SCIRP are listed as below. Submit your manuscript to us via either submit@scirp.org or Online Submission Portal.
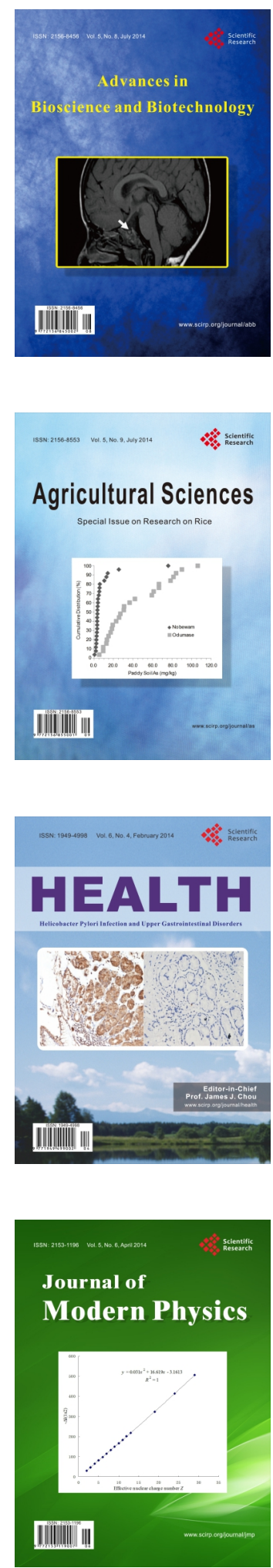
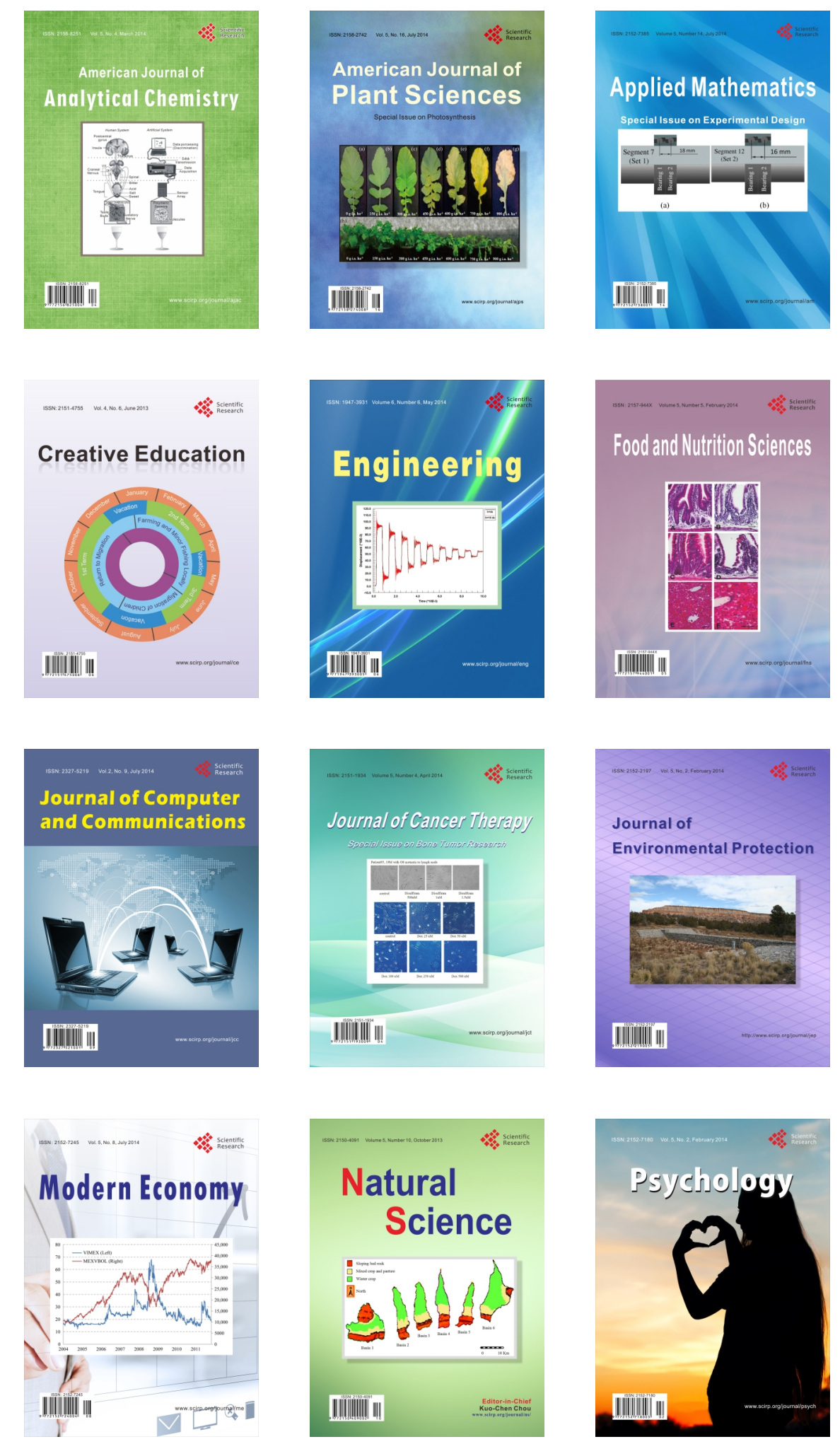